\title{
A structural view of ligand-dependent activation in thermoTRP channels
}

\author{
Ximena Steinberg ${ }^{1,2}$, Carolyne Lespay-Rebolledo ${ }^{3}$ and Sebastian Brauchi ${ }^{1 *}$ \\ ${ }^{1}$ Faculty of Medicine, Institute of Physiology, Universidad Austral de Chile, Campus Isla Teja, Valdivia, Chile \\ 2 Faculty of Sciences, Graduate School, Universidad Austral de Chile, Campus Isla Teja, Valdivia, Chile \\ ${ }^{3}$ Faculty of Chemical and Pharmaceutical Sciences, Graduate School, Universidad de Chile, Santiago, Chile
}

\section{Edited by:}

Harley Takatsuna Kurata, University of British Columbia, Canada

\section{Reviewed by:}

Leon D. Islas, National Autonomous University of Mexico, Mexico

Miguel Angel Valverde, Universitat

Pompeu Fabra, Spain

Elena Oancea, Brown University,

USA

\section{${ }^{*}$ Correspondence:}

Sebastian Brauchi, Faculty of

Medicine, Institute of Physiology,

Universidad Austral de Chile,

Campus Isla Teja, Biomedical

Sciences Building, Valdivia 511-0566,

Chile

e-mail:sbrauchi@uach.cl
Transient Receptor Potential (TRP) proteins are a large family of ion channels, grouped into seven sub-families. Although great advances have been made regarding the activation and modulation of TRP channel activity, detailed molecular mechanisms governing TRP channel gating are still needed. Sensitive to electric, chemical, mechanical, and thermal cues, TRP channels are tightly associated with the detection and integration of sensory input, emerging as a model to study the polymodal activation of ion channel proteins. Among TRP channels, the temperature-activated kind constitute a subgroup by itself, formed by Vanilloid receptors 1-4, Melastatin receptors 2, 4, 5, and 8, TRPC5, and TRPA1. Some of the so-called "thermoTRP" channels participate in the detection of noxious stimuli making them an interesting pharmacological target for the treatment of pain. However, the poor specificity of the compounds available in the market represents an important obstacle to overcome. Understanding the molecular mechanics underlying ligand-dependent modulation of TRP channels may help with the rational design of novel synthetic analgesics. The present review focuses on the structural basis of ligand-dependent activation of TRPV1 and TRPM8 channels. Special attention is drawn to the dissection of ligand-binding sites within TRPV1, $\mathrm{PIP}_{2}$-dependent modulation of TRP channels, and the structure of natural and synthetic ligands.

Keywords: TRP channels, TRPV1, TRPM8, structure, PIP 2 , capsaicin, menthol

\section{TRP CHANNELS}

Mammalian TRP channel proteins are polymodal cation channels that participate in sensory physiology at different levels. This includes thermo-sensation, mechano-sensation, nociception, touch, taste, olfaction, and vision (Clapham, 2003; Voets et al., 2005). Other than a loose sequence homology, predicted channel architecture, and non-selective cation permeability, there are no particular features defining the TRP family. The 28 known mammalian TRP channels are grouped by homology into six sub-families named $\mathrm{C}, \mathrm{M}, \mathrm{V}, \mathrm{A}, \mathrm{P}$, and $\mathrm{ML}$, for canonical, melastatin related, vanilloid binding, ankyrin repeat, polycystin, and mucolipin, respectively, (Ramsey et al., 2006). By integrating multiple stimuli they supply signal amplification through calcium permeation and membrane depolarization.

Abbreviations: ARD, ankiryn repeat domain; BCTC, 4-(3-chloro-pyridin-2-yl)piperazine-1-carboxylic acid (4-tert-butyl- phenyl)-amide; CaV, Voltage-gated calcium cannel; CNG, cyclic nucleotide-gated cannel; CPZ, Capsazepin; Cryo-EM, Cryo-electron microscopy; DkTx, double-knot vanollotoxin; G-V, ConductanceVoltage curve; HCN, Hyperpolarization-activated and cyclic nucleotide-gated cannel; Kir, inwardly rectifying potassium cannel; Kv, Voltage-gated potassium cannel; LPA, lysophosphatidic acid; MD, molecular dynamics; Menthol, 1R,2S,5R-2-isopropyl-5-methylcyclohexanol; NADA, N-arachidonoyl-dopamine; NPPB, 5-nitro-2-(3-phenylpropylamino) benzoic acid; PIP2, phosphatidylinositol biphosphate; PI(4,5)P2, phosphatidylinositol 4,5-biphosphate; PUFA, polyunsaturated fatty acids; RTX, resiniferatoxin; SAR analysis, Structure-activity relationship analysis; SCAM, substituted cysteine accessibility method; TD, TRP-domain; TM, transmembrane-spanning hélix; TRP, Transient Receptor Potential; VSD, Voltage-sensing Domain.
Cooperativity intrinsic to TRP channels may result in allosteric coupling of distinct activation stimuli. A good example of the allosteric nature of TRP channels would be the case of temperature-activated TRP channels (thermoTRPs) (Latorre et al., 2007; Pertusa et al., 2012).

Together with their role in sensory and pain physiology (Cesare and McNaughton, 1996; Caterina et al., 1997; Tominaga et al., 1998; De Petrocellis et al., 2008; Julius, 2013) TRP channel function is underscored by the prevalence of various diseases, for example hypomagnesemia, polycystic kidney disease, and mucolipidosis, caused by mutation of TRP proteins (Montell, 2005; Nilius, 2007). All this is accompanied by recent advances on menthol-based cancer treatments (Journigan and Zaveri, 2013). Consequentially, the role of TRP channels in the regulation of several sensitive processes as well as in physiopathology has led to the identification of a diverse set of ligands with potential therapeutic applications (Messeguer et al., 2006; Nilius, 2007; Latorre et al., 2009; Alawi and Keeble, 2010).

\section{GENERAL ARCHITECTURE OF TEMPERATURE-ACTIVATED TRP CHANNELS}

After the cloning of the capsaicin receptor TRPV1 (initially dubbed VR1) by the group of David Julius (Caterina et al., 1997), several TRP channels have been identified as thermal sensors. To date, temperature-activated TRP channels correspond to a subgroup of 10 TRP channels which are expressed in sensory 
nerve endings and skin cells, and are characterized by distinctive high temperature-dependent activation $\left(\mathrm{Q}_{10}>10\right)$. ThermoTRP channels display different dynamic ranges for their temperature activation profile (Pertusa et al., 2012), are activated by several natural compounds (Hwang et al., 2000; Palazzo et al., 2013; Ramachandran et al., 2013), and are also identified through their participation in nociceptive pathways (Cesare and McNaughton, 1996; Caterina and Julius, 1999; Di Marzo et al., 2002; Immke and Gavva, 2006; Mandadi and Roufogalis, 2008; Dux et al., 2012; Straub et al., 2013).

One interesting feature of thermoTRP channels is the presence of members from at least four different TRP families ( $V$, M, A, and C). Whereas TRPV1-4, TRPM2, TRPM4, and TRPM5 are heat-activated, TRPM8, TRPA1, and TRPC 5 are activated by cold (Patapoutian, 2005; Clapham, 2009; Zimmermann et al., 2011; Pertusa et al., 2012). We focus our attention on TRPV1 and TRPM8, the most studied thermal receptors for hot- and cold-sensing, respectively (Latorre et al., 2009).

Phylogenetic studies, transmembrane segment prediction, and structural data indicates that TRP channels are related to the superfamily of voltage-gated cation channels, for example voltage-gated potassium $\left(\mathrm{K}_{\mathrm{V}}\right)$ and voltage-gated calcium $\left(\mathrm{Ca}_{\mathrm{V}}\right)$ channels (Phillips et al., 1992; Wes et al., 1995; Harteneck et al., 2000; Ramsey et al., 2006; Liao et al., 2013). Biochemical, optical, and structural information support the notion of a tetrameric channel architecture (Jahnel et al., 2001; Kedei, 2001; Amiri et al., 2003; Veliz et al., 2010; Liao et al., 2013). TRP channels are diverse in their design and numerous structural features vary between members of different sub-families. However, the functional TRP channel is formed by the coassembly of four subunits, each comprising six transmembrane-spanning (TM) helices with intracellular amino- and carboxyl-terminus domains (Harteneck et al., 2000). By analogy to the 6TM architecture of $\mathrm{K}_{\mathrm{v}}$ channels, TM5 and TM6 constitute the pore region. Electrophysiological and structural data further support this topology (Owsianik et al., 2006; Susankova et al., 2007; Salazar et al., 2009; Liao et al., 2013; Figure 1A). Since TRP channels are considered distant relatives of $\mathrm{K}_{\mathrm{v}}$ channels and elicit voltage-dependent activation $(z d=$ $0.4 \mathrm{e}-0.9 \mathrm{e})$, the TM1-TM4 region has been suggested to serve as a voltage-sensing domain (VSD) (Voets et al., 2007; Boukalova et al., 2013). However, chimeras between TRPM8, TRPV1, and $\mathrm{K}_{\mathrm{v}} 1.2$ in which TM1-TM4 of TRPM8, and TRPV1 is replaced with TM1-TM4 of $\mathrm{K}_{\mathrm{V}} 1.2$ produced non-functional TRP channels suggesting that the $\mathrm{K}_{\mathrm{V}} 1.2 \mathrm{VSD}$ is insufficient to restore TRP channel function (Kalia and Swartz, 2013). The structure of TRPV1 lacks a patch of charged amino acids, located in the TM1-TM4 domain, typically associated with voltage-sensitivity in $K_{v}$ channels. Thus, evidence indicates that TRP channels likely utilize a different mechanism to sense voltage. Given a hypothetical scenario in which the TM1-TM4 domain behaves statically, as it apparently does when ligands or toxins bind to the channel (Cao et al., 2013b), it is probably not TM1-TM4 but the pore region undergoing voltage-dependent structural rearrangements. It is important to note here that most of the work claiming voltagedependent changes caused by mutagenesis underscore a shift in the conductance-voltage $(\mathrm{G}-\mathrm{V})$ curve along the voltage axis as an indication of voltage dependence. This should be taken with
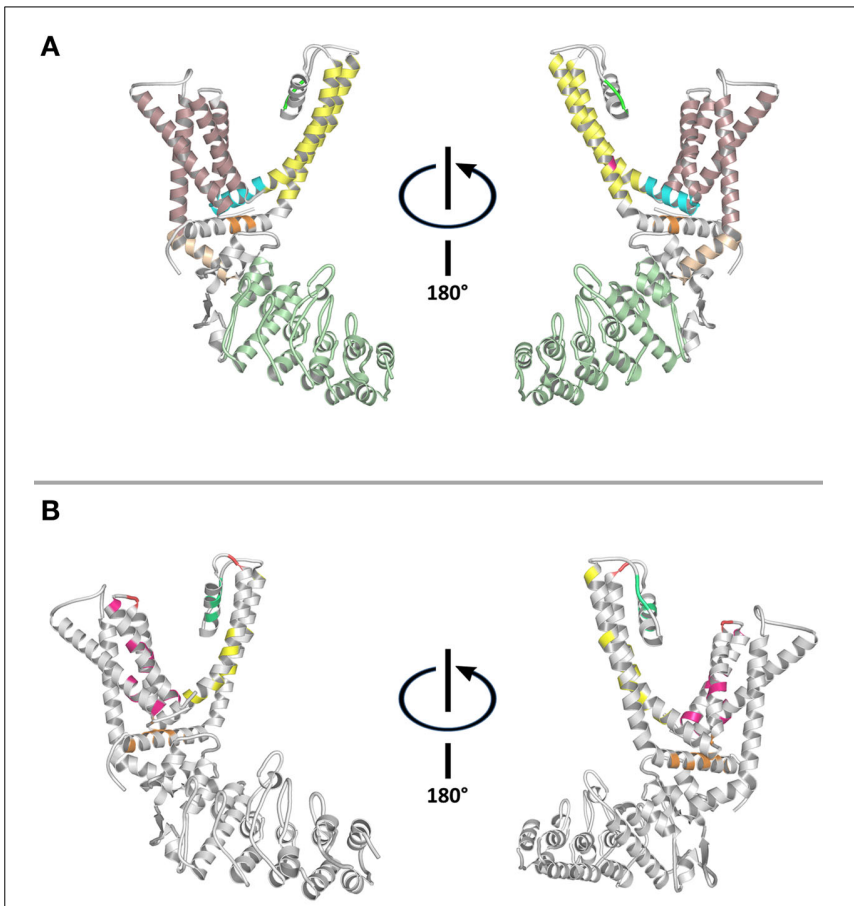

C

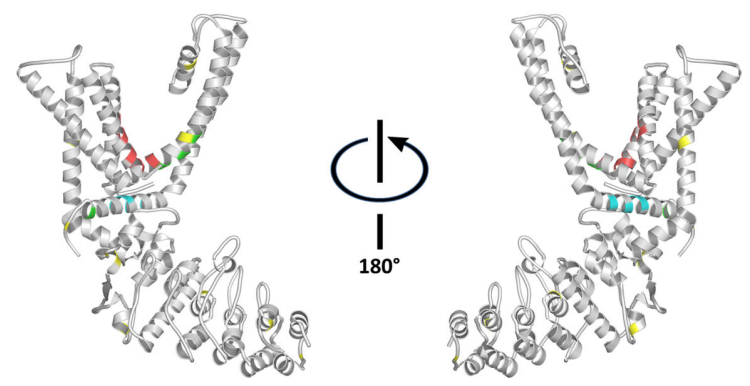

FIGURE 1 | Structural features of the capsaicin receptor. (A) Conserved structural domains: Ankyrin repeat domain-Olive. Pre-TM1 helix-Salmon. TM1-TM4 domain-Pale pink. TM4-TM5 linker-Cyan. Selectivity filter-Green. Gate-Fuchsia. TM5-TM6 domain-Yellow. TRP domain-Orange. (B) Residues involved in ligand-binding and/or modulation of channel activity: Colors represent residues location. TM1-TM4 domain—Fuchsia. Selectivity filter and pore helix—Green. TM5-TM6 domain-Yellow. Intracellular loops—Orange. Extracellular loops—Red. (C) Putative ligand-binding sites: Vanilloids-Red. Fatty acids and lipids-Green. PIP 2 -Cyan. Cysteine residues-Yellow. TRPV1 structure (PDB ID 3J5P) was visualized and colored using PyMOL Molecular Graphics System.

caution since this observation alone may suggest a direct effect on allosteric coupling rather than gating charge suppression.

Alanine-scanning mutagenesis of the TRPV1 pore domain identified three residues critically involved in capsaicin, thermal and pH activation: Y671, I672, and N676 (Susankova et al., 2007). Interestingly, the mutation Y671A dramatically reduces capsaicin TRPV1 response, and the characteristic heat potentiated response to agonist is abolished. Promotion of agonist 
desensitization when repeated capsaicin pulses were applied caused heat-induced potentiation recovery. The authors hypothesized that Y671 may be involved in the allosteric mechanism coupling thermal and agonist activation (Susankova et al., 2007). This observation was particularly interesting since SCAM analysis (Substituted Cysteine Accessibility Method) performed by the Rosenbaum group (Salazar et al., 2009) locates that residue in the narrowest region of the pore. The recent cryo-electron microscope (cryo-EM) structure of TRPV1 (Cao et al., 2013b; Liao et al., 2013) shows a constriction point at position Y671, but suggests that the narrowest constriction lies right below, at residue I679.

In addition, it has been suggested that packaging and coupling of the TM1-TM4 module differs considerably between $\mathrm{K}_{\mathrm{v}} 1.2$ and TRP channels (Kalia and Swartz, 2013). This is in good agreement with fluorescence spectrometry functional experiments in which the authors measured a set of intermolecular distances between $\mathrm{C}$ - and N-terminal and with respect to the plasma membrane, and fitted those to the low resolution cryo-EM TRPV1 structure (Moiseenkova-Bell et al., 2008; De-la-Rosa et al., 2013). The results suggest that the molecular packaging of TRPV1 should be more constrained than other voltage-dependent channels.
The recent $3.4 \AA$ resolution structure of TRPV1 confirms these functional experimental-based predictions; comparison of unliganded (apo) and ligand-bound complexes suggests that the TM1-TM4 domain acts as a rigid body during activation (Cao et al., 2013b).

The TM1-TM4 domain has been mapped to contain most of the ligand binding-related residues (Winter et al., 2013), emerging as a ligand-binding domain (LBD) for TRP channels (Figure 1). Furthermore, sensitivity to ligands is maintained by transferring TM3-TM4 moieties of TRPM8, and TRPV1 onto $\mathrm{K}_{\mathrm{v}} 1.2$ (Kalia and Swartz, 2013). TRPV1's structure reveals that the ligandbinding pocket is located near the TM3-TM4 transmembrane region, and the TM4-TM5 linker (Figures 1B,C). Closer inspection of the reported structures suggest that intra- and inter subunit contacts between the ankyrin repeat domain (ARD)-TM1 linker, TM4-TM5 linker, and proximal C- terminal region might be modified in response to agonists.

\section{MOLECULAR MODELING OF TRP CHANNELS}

Structures belonging to the superfamily of potassium channels, for example Shaker-like $\mathrm{K}_{\mathrm{v}} 1.2$ (Long et al., 2005; Chen et al., 2010), cyclic nucleotide-gated (CNG) (Clayton et al., 2008), and

Table 1 | Templates used for homology modeling of TRPs and the packing of LBD of TRPV1 and TRPM8 channels.

\begin{tabular}{|c|c|c|c|c|c|}
\hline \multirow{2}{*}{$\begin{array}{l}\text { Protein } \\
\text { TRPV1 }\end{array}$} & \multirow{2}{*}{$\begin{array}{l}\text { Method used } \\
\text { Homology modeling }\end{array}$} & \multicolumn{2}{|c|}{$\begin{array}{c}\text { Structure or structural } \\
\text { template with PDB identifier }\end{array}$} & \multirow{2}{*}{$\begin{array}{l}\text { Packing of LBD } \\
\mathrm{n} / \mathrm{d}\end{array}$} & \multirow{2}{*}{$\begin{array}{l}\text { References } \\
\text { Brauchi et al., } 2007\end{array}$} \\
\hline & & $\begin{array}{l}\text { - S1-S6 } \\
\text { - C- termini }\end{array}$ & $\begin{array}{l}\text { 2R9R (Kv1.2) } \\
\text { 1Q3E (HCN2) }\end{array}$ & & \\
\hline TRPV1 & Homology modeling & $\begin{array}{l}\text { - N-termini (TMP kinase) } \\
\text { - Ankyrin domain (TRPV1 ARD) } \\
\text { - S1-S6 (Kv1.2) } \\
\text { - Proximal C-termini (synthetic) } \\
\text { - Distal C- termini1 (HCN2 } \\
\text { channel) }\end{array}$ & $\begin{array}{l}\text { 1E9C } \\
\text { 2PNN } \\
\text { 2R9R } \\
\text { 1WL5 } \\
\text { Q3E }\end{array}$ & Loose & $\begin{array}{l}\text { Fernández-Ballester } \\
\text { and Ferrer-Montiel, } \\
2008\end{array}$ \\
\hline TRPV1 & CryoEM & $\begin{array}{l}\text { - Ankyrin domain (TRPV1 ARD) } \\
\text { - S1-S6 (Kv1.2) }\end{array}$ & $\begin{array}{l}\text { 2PNN } \\
\text { 2R9R }\end{array}$ & $n / d$ & $\begin{array}{l}\text { Moiseenkova-Bell } \\
\text { et al., } 2008\end{array}$ \\
\hline TRPM8 & Homology modeling & $\begin{array}{l}13 \text { different protein fragments. } \\
\text { Including: } \\
\text { - S3 and S4 (Kv1.2) } \\
\text { - C- termini (HCN2-cAMP) }\end{array}$ & $\begin{array}{l}\text { 2R9R } \\
1050\end{array}$ & Loose & Pedretti et al., 2009 \\
\hline TRPM8 & TRPM8 and TRPM8-ago nist MD simulations & TRPV1 homology model by Ped & ti et al. (2009). & Loose & Pedretti et al., 2011 \\
\hline TRPV1 & Fluorescence spectroscopy and CryoEM & $\begin{array}{l}\text { - Ankyrin domain } \\
\text { - S1-S6 }\end{array}$ & $\begin{array}{l}\text { 2PNN } \\
\text { 2R9R }\end{array}$ & Constrained & $\begin{array}{l}\text { De-la-Rosa et al., } \\
2013\end{array}$ \\
\hline $\begin{array}{l}\text { TRPM8 } \\
\text { TRPV1 }\end{array}$ & $\begin{array}{l}\text { Homology modeling and further testing } \\
\text { by chimeric constructs }\end{array}$ & $\begin{array}{l}\text { Independently: } \\
\text { (Kv1.2) } \\
\text { (MLotiK) }\end{array}$ & $\begin{array}{l}\text { 2R9R } \\
\text { 3CL1 }\end{array}$ & Constrained & $\begin{array}{l}\text { Kalia and Swartz, } \\
2013\end{array}$ \\
\hline TRPV1 & CryoEM for apo TRPV1 channel & 2R9P & & - & Liao et al., 2013 \\
\hline TRPV1 & CryoEM for RTX/DkTx bonded TRPV1 channel & $2 \mathrm{R} 9 \mathrm{O}$ & & - & Cao et al., 2013b \\
\hline TRPV1 & CryoEM for capsaicin bonded TRPV1 channel & 2R9R & & - & Cao et al., 2013b \\
\hline
\end{tabular}

$n / d$, not described.

An extensive overview on the structure of TRP channels fragments with high resolution data can be found in "Structural Biology of TRP channels," by Li et al. (2011). 
hyperpolarization-activated (HCN) (Zagotta et al., 2003) channels have been used as templates to make homology models of the full transmembrane domain of TRPV1 including N-terminal ankyrin repeats, and the C-terminal TRP domain (Table 1). The first structural data on TRPV1 came from cryo-EM, giving support to the generalities accounted for by researchers when modeling TRPs (Moiseenkova-Bell et al., 2008). The evident similarities between TRPV1's low resolution cryo-EM and the structural arrangement of $\mathrm{K}_{\mathrm{V}} 1.2$ is now reinforced by the recent higher resolution cryo-EM data (Liao et al., 2013). It is very important to keep in mind the fact that cryo-EM require the acquisition of multiple pictures of the electronic density of protein's surface, to finally build enriched electron density maps, allowing the $3 \mathrm{D}$ reconstruction of the molecule. Therefore, the exact position of the side chains are not resolved in detail, and must be modeled instead of being fitted with precision as is achievable with X-ray crystallography. In this sense, the novel structure can be considered as a well refined model obtained under strict constrains. Nevertheless, the novel TRPV1 cryo-EM structures provide valuable information about the tetrameric architecture and ligand-binding regions, promoting the re-evaluation of current models and their predictions (Cao et al., 2013b; Liao et al., 2013; Table 1).

Molecular modeling is an extremely useful methodology for complementing experimental techniques as it provides a potential structural context for interpreting experimental results. The high sequence homology among TRPVs will allow researchers to construct molecular models of other members of the TRPV sub-family and help bridge the structure-function paradigm. Furthermore, the promiscuous behavior among TRP channels toward ligands suggests a conserved LBD and lends support to future molecular models of TRP channels. However, molecular models for TRP channels members of other sub-families should be constructed with extreme caution because low resolution EM structures obtained for other TRP channels such as TRPC3 and TRPM2, present a different three dimensional arrangement, looking awkwardly bulky (Maruyama et al., 2007; Mio et al., 2007).

\section{THE TRP DOMAIN AND PIP ${ }_{2}$-DEPENDENT MODULATION OF thermoTRP CHANNELS}

Ligands of lipidic nature act as endogenous regulators of thermoTRP channel activity (Lukacs et al., 2013; Poveda et al., 2013). For the case of TRPV1, this includes negatively charged lipids such as phosphatidylinositol 4,5-bisphosphate $\left[\mathrm{PIP}_{2}, \mathrm{PI}(4,5) \mathrm{P}_{2}\right]$, lysophosphatidic acid (LPA), and $N$-arachidonoyl-dopamine (NADA) (well reviewed by Morales-Lázaro et al., 2013). As one of the most important endogenous ligands, we focus our attention on the $\mathrm{PIP}_{2}$-dependent modulation of channel activity and structural features of the TRP domain.

The TRP domain, a 25 amino acid sequence located immediately after the TM6 transmembrane helix is a shared feature among channels from the $\mathrm{C}, \mathrm{V}$, and $\mathrm{M}$ subfamilies. This domain contains the TRP box, a highly conserved region originally dubbed the "EWKFAR motif" (Zhu et al., 1995). The TRP box is defined by the consensus sequence WKFQR, in which tryptophan is the most conserved residue. The positive charges at positions 2 and 5 of the sequence are shared by almost all TRPs having a TRP domain including TRPV1 and TRPM8 channels, and have been suggested as part of the $\mathrm{PIP}_{2}$ sensor of the channel (Latorre et al., 2009).

$\mathrm{PIP}_{2}$ is an abundant, short-lived phospholipid present in the plasma membrane of cells (Le Roy and Wrana, 2005), playing a central role in regulating ion channel activity (Kruse et al., 2012). It has been shown that most TRP channels from the $C, M$, and $\mathrm{V}$ families are regulated by $\mathrm{PIP}_{2}$ (Nilius et al., 2008; Rohacs, 2009; Morales-Lázaro et al., 2013). The hypothesis is that positively charged residues present in the TRP domain are responsible for $\mathrm{PIP}_{2}$-dependent modulation of TRP channel activity (Rohacs et al., 2008; Latorre et al., 2009) sensitizing TRPV and TRPM channels (Ferrer-Montiel et al., 2004; Rohács et al., 2005; Brauchi et al., 2007; Rohacs et al., 2008; Stein et al., 2009; Ufret-Vincenty et al., 2011; Fujita et al., 2013). Recently by biochemistry, electrophysiology, and FRET imaging, a positively charged aminoterminal sequence has been identified in TRPV4, and proposed as $\mathrm{PIP}_{2}$ binding pocket (Garcia-Elias et al., 2013). Thus, as suggested for other TRPs, upon $\mathrm{PIP}_{2}$ interaction a reconfiguration favoring channel activation occurs. Of worthy note is the fact that the TRP domain may be bimodal; for example Doerner et al. clearly demonstrate that TRPV3 channels are sensitized by depletion of $\mathrm{PIP}_{2}$ in a TRP domain-specific fashion (Doerner et al., 2011). Additionally, the work of David Julius shows a desensitizing effect of $\mathrm{PIP}_{2}$ over TRPV1 activation (Prescott and Julius, 2003; Cao et al., 2013a). Such an effect, demonstrated on intact cells and liposome reconstituted channels, is thought to be mediated by the distal portion of the C-terminal domain, absent in the cryo-EM structure of the channel. Thus, it is still an interesting matter of discussion how $\mathrm{PIP}_{2}$ binding promotes potentiation or reduction of ionic currents derived from thermal, agonist, or voltage activation.

It has been proposed that $\mathrm{PIP}_{2}$ determines intra- and intermolecular connectivity, controlling allosteric coupling within TRP channels (Brauchi et al., 2007; Garcia-Sanz et al., 2007; Latorre et al., 2009; Figure 2). The availability of a cryo-EM TRPV1 structure in its apo, closed state, and 3D reconstructions of activated states in complex with the vanilloid agonists resiniferatoxin (RTX), and capsaicin permits comparison of different functional states of TRPV1 (Cao et al., 2013b). This approach is likely to enhance understanding of the activation of TRP channels by different agonists and identify potential gating sites. Inspection of apo and ligand-bound structures of TRPV1 (Cao et al., 2013b; Liao et al., 2013; PDB IDs: 3J5P, 3J5Q, and 3J5R), identified a binding pocket suitable to fit one $\mathrm{PIP}_{2}$ molecule connecting TM5 and TM6 from one subunit with the TM5-TM6 linker of the neighbor subunit (Figure 2A). This binding pocket is similar to the one predicted earlier by molecular docking and molecular dynamics (MD) simulations (Brauchi et al., 2007), and is in good agreement with the position of $\mathrm{PIP}_{2}$ molecules in the crystal structures of inwardly rectifying potassium channels Kir2.2 and Kir3.2 (Hansen et al., 2011; Whorton and MacKinnon, 2011; PDB IDs: 3SPI, and 3SYA).

In the case of Kir channels, the phosphoinositide is coordinated by residues located on the lower part of the outer helix and tether helix, establishing inter-molecular interactions through 


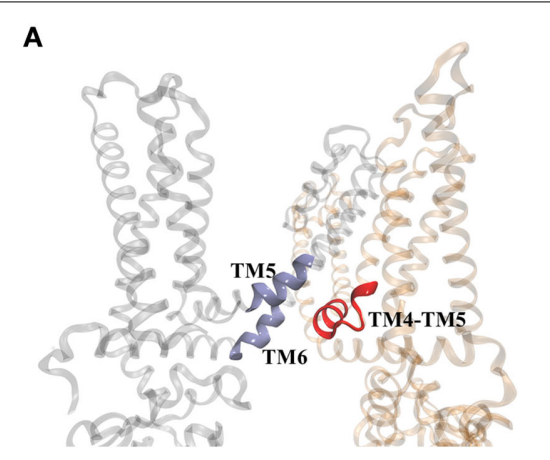

C

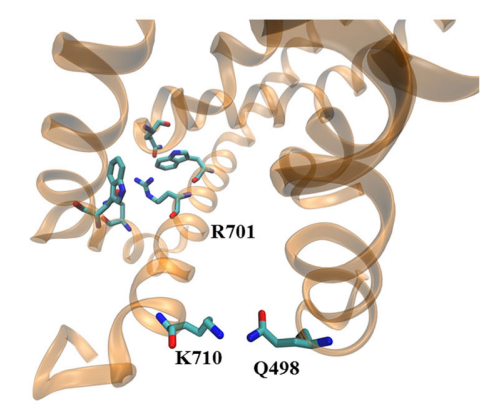

FIGURE 2 | $\mathrm{PIP}_{\mathbf{2}}$ mediates intra- and inter-subunit contacts.

(A) Identified $\mathrm{PIP}_{2}$ binding pocket in the structure of TRPV1.

(B) Residues proposed as mediators of $\mathrm{PIP}_{2}$ interaction to the channel. (C) K710 is located at the distal end of the TD helix and interacts with Q498 located at the bottom of TM2. (D) Predicted/potential cation- $\pi$ interactions connecting the TRP box of the TD helix with the TM4-TM5

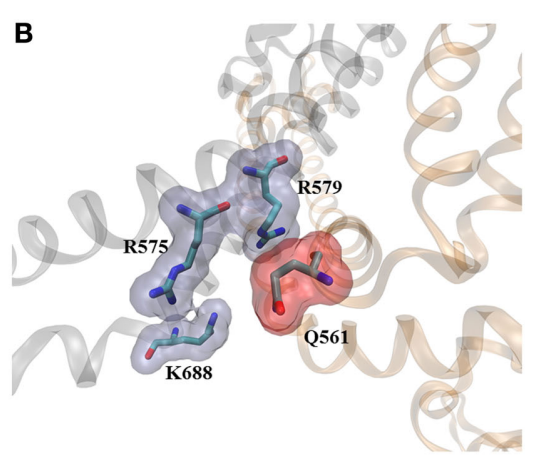

D

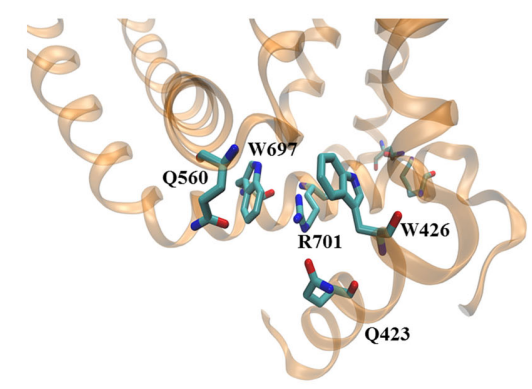

helix and N-terminal region. In order to get a better placement of the lateral chains of the available structure, the TRPV1 channel (PDB ID 3J5P) was embedded in lipids (POPC), and placed in a periodic box containing water and ions $(140 \mathrm{mM} \mathrm{KCl})$. After $5 \mathrm{~ns}$ of all-atom MD simulations using the NAMD/CHARMM32 force-field, the channel was visualized using VMD. bonding to the IF-helix of the neighboring subunit (see note below $^{1}$ ) Our previous work (Brauchi et al., 2007), and preliminary MD simulations on the recent structural data shows that TRPV1's putative binding pocket for PIP $_{2}$ elicit a patch of four charged residues (Q561, R575, R579, and K688), readily available for the coordination of the negatively charged head group of the lipid (Figures 2A,B). Interestingly, as in Kir channels, these residues are located in different subunits making possible the existence of a bridge between them as we envisioned before (Brauchi et al., 2007; Latorre et al., 2009). In support of this hypothesis, mutational studies within this region identified amino acids producing strong desensitization of the channel (Q560, Q561, R575, R579, K688, W697, R701, and K710; Winter et al., 2013). According to these results, R701 and K710 located in the TRP domain are also predicted as $\mathrm{PIP}_{2}$ binding residues. However, according to our view, it seems that there is little space for them to interact with the polar head group of the lipid.

The three dimensional arrangement of the TRP domain helix (TD helix) in the context of the TRPV1 structure allows us to

\footnotetext{
${ }^{1}$ Note: Kir Channels posses only two transmembrane helices the outer, similar to TM5, and the inner helix, akin to TM6. These helices are associated to the intracellular domains of the channel by helical linkers. While the tether helix connects the inner helix with the cytoplasmatic C-terminal, the interfacial (IF) helix connects the outer helix with the cytoplasmatic N-terminal.
}

draw an alternative hypothesis. The structure shows the location of the TRP box defined by the sequence ${ }^{697} \mathrm{WKLQR}^{701}$ at the central portion of the TD helix, followed by the sequence ${ }^{702}$ AITILDTEK ${ }^{710}$ on the second half (Figure $2 \mathrm{C}$ ). The charged residues $\mathrm{R} 701$ and $\mathrm{K} 710$ have been suggested as negatively charged residues coordinating $\mathrm{PIP}_{2}$, however they appear closer to the aromatic residues W697 (TD helix) and W426 (Nterminal). This is a suitable situation for the formation of cation- $\pi$ interactions controlling TRPV1's gate (Figure 2C) and represent an interesting structural feature to explore. Recent reports from the group of A. Ferrer-Montiel (Valente et al., 2008; Gregorio-Teruel et al., 2014) showed that amino acids I696 and W697, located within the TD helix, are essential for channel's function, probably by controlling the correct allosteric coupling of the ligand-dependent conformational change and voltage-sensor movement to the channel's gate, suggesting that they are part of a more complex intra- or inter-molecular network of connectivity. The TD helix is positioned horizontal to the plane of the membrane. In order to promote and/or control channel gating we envisioned a sliding movement of the TD helix either linear, or lateral with a pivot joint around K710. This sliding helix would be controlled by interactions associated to W697, acting as a latch. More than half of the cation- $\pi$ pairs involve arginine residues and about one-third asparagine or glutamine residues carrying a partial charge (Dougherty, 
1996). Although the resolution of the cryo-EM structure is insufficient to accurately place the side chains rotamers, it is tempting to suggest that the hypothetical cation- $\pi$ core identified in this region may be helped by the presence of residues Q560 (TM4-TM5 linker) and Q423 (N-terminus). The residues Q560 and Q423 (together with W426), are located at the bottom of the ligand binding pocket, and close to a region that has been associated with thermal sensitivity, respectively (Yao et al., 2011), interestingly, the modification of any of these residues induce strong desensitization of the channel (Winter et al., 2013). Thus, we envision a cluster of cation $-\pi$ interactions as the molecular switch connecting different stimuli to the gate. At the C-terminal end of the TD helix K710 appears to be in close proximity to Q498, located in the TM2-TM3 linker (Figure 2D). It is possible that upon $\mathrm{PIP}_{2}$ binding to the proximal TD helix the interactions observed in the TRP box will be re-shaped, unlocking the TD helix leading to channel opening. Such negative control of the gate by the TD helix has been suggested previously (Garcia-Sanz et al., 2007). Further studies addressing the details defining the mechanics of this fundamental region are required for a deeper understanding of TRP channel gating.
A

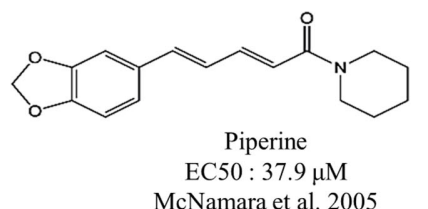

HO-<smiles>CC(C)=CCCC(C#N)=CCCC(C)=CCc1c(C)cc(C)cc1O</smiles>

A Szallasi et al. 1999<smiles>CC(C)=CCCC(C)=CCCC(C)=CCc1c(C)c(O)c(O)c(O)c1C=O</smiles>

A Szallasi et al. 1999

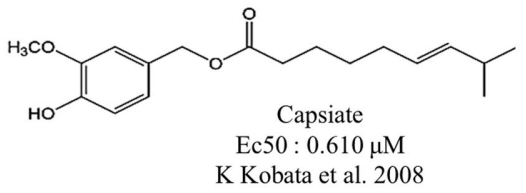

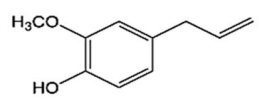

Eugenol

Ec50: $1 \mathrm{mM}$

Yang et al. 2003<smiles>CCCCC(O)CC(=O)CCc1ccc(O)c(OC)c1</smiles>

A Morita et al. 2007<smiles>CCC=CC(=O)CCc1ccc(O)c(OC)c1</smiles><smiles>COc1cc(CCC(C)=O)ccc1O</smiles>

Ec50: $>1 \mathrm{mM}$

VN Denov et al. 2002

B

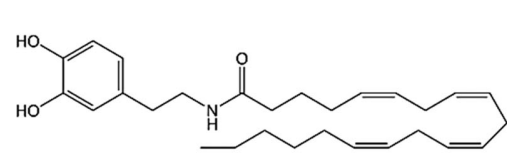

$\mathrm{N}$-arachidoyldopamine (NADA)

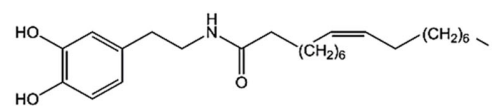

N-oleoyldopamine

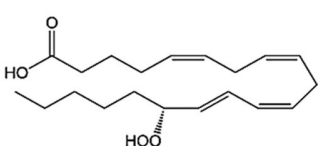

15-(S)-HPETE

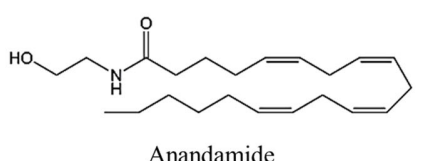

Anandamide<smiles>CCCCC/C=C\C=C\[C@@H](O)CCCC(=O)O</smiles>

LTB4

FIGURE 3 | The structure of natural and endovaniloids. (A) Natural compounds with agonist activity on TRPV1 receptors. Figure indicates the affinity for specific $^{3}[\mathrm{H}]$-resiniferatoxin binding sites in rat spinal cord (Szallasi and Blumberg, 1999). (B) Structure of endovanilloids identified as activators of TRPV1 receptors. 
A

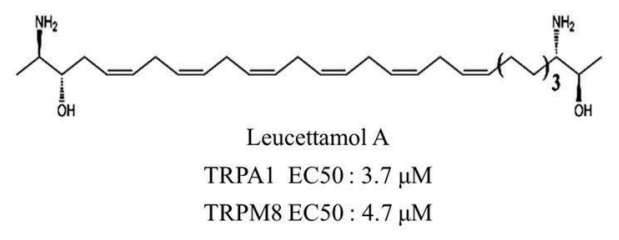<smiles>CC(CC=CCC(C)C(C)C)CCCCCCCCCCC(C)C(C)C</smiles>

Leucettamol B

TRPV1 EC50 $: 4.8 \mu \mathrm{M}$

TRPA1 EC50 : $3.5 \mu \mathrm{M}$

TRPM8 EC50 : $32.6 \mu \mathrm{M}$

B<smiles>O=CC=Cc1ccccc1</smiles>

Cinnamaldehyde

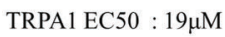

C<smiles>CC12CCC(CC1)C(C)(C)O2</smiles><smiles>CC1CCC(C(C)C)C(=O)C1</smiles>

1,8 -Cineole<smiles>CCCc1ccc(O)c(O)c1</smiles>

Eugenol<smiles>CC1CCC(C(C)(C)C)CC1</smiles>

Terpineol<smiles>CC(C)C1CC(C)C(C)C(C)C1C</smiles>

(-)- $\alpha$-Thujone

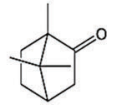

Camphor

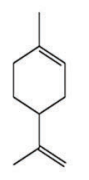

(+)-Limonene<smiles>CC1CC2CCC1(C)C2(C)C</smiles>

(+)-Borneol<smiles>CC(C)=CCCC(C)C</smiles>

(+)-Linalool

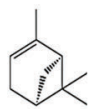

(-)- $\alpha$-Pinene

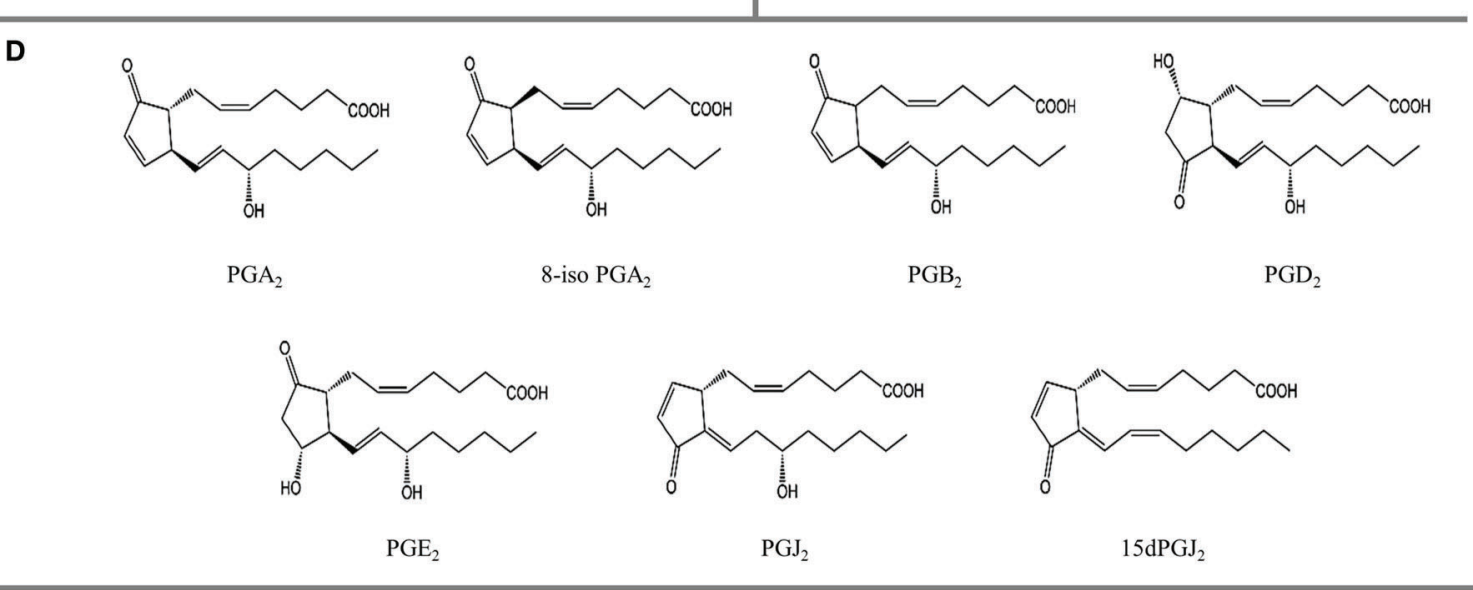

E<smiles>CCC(C)C1CCC(C)CC1O</smiles>

Thymol

TRPV3 EC50 : $84.1 \mu \mathrm{M}$

TRPA1 EC50 : $3.1 \mu \mathrm{M}$

TRPM8 EC50 : $52.2 \mu \mathrm{M}$<smiles>CC1CCC(C(C)C)C(O)C1</smiles>

Menthol

TRPV3 EC50 : $65 \mu \mathrm{M}$

TRPM8 EC50 : $196 \mu \mathrm{M}$
FIGURE 4 | The structure of natural thermoTRP ligands. (A) Leucettamol A and B identified with TRP channel activity (Chianese et al., 2012). (B) Cinnamaldehyde, TRPA1 activator (Macpherson et al., 2007). (C) Structure of monoterpenoids and related compounds evaluated on TRPM8, TRPV3, and TRPA1 receptors
(Vogt-Eisele et al., 2007; Takaishi et al, 2012). (D) Structure of prostaglandins evaluated in TRPA1 receptors (Taylor-Clark et al., 2008). (E) Activity profile of human TRPA1 and mouse TRPM 8 channels after addition of thymol (Lee et al., 2008) and menthol (Sherkheli et al., 2010), respectively.

\section{A LIGAND BINDING DOMAIN}

Capsaicin, a pungent ingredient of chili peppers, is the natural agonist of TRPV1 channels and is responsible for the spiciness of the plant's fruit. Essential research using capsaicin-insensitive animal models, site-directed mutagenesis, and structural data pinpoint residues located in the TM4-TM5 linker, and TM3 helical residues Y511 and S512 which may stabilize the binding of capsaicin via polar interactions and hydrophobic contacts, respectively (Jordt and Julius, 2002; Cao et al., 2013b). Residues M547 and T550 in TM4 have also been mentioned as part of 
the vanilloid binding mechanism (Gavva et al., 2004; Cao et al., 2013b). Cao and colleagues suggested that upon capsaicin (or the natural vanilloid resiniferatoxin, RTX) binding to the TM3TM4 helix and TM4-TM5 linker, hydrogen interactions between the linker and the TM6 helix terminal region are disrupted, presumably promoting gate opening. When comparing TRPV1 ligand-bound cryo-EM structures, it could be observed that capsaicin binding led to gate opening without major changes in selectivity filter conformation and diameter. In contrast, resineferatoxin (RTX/DkTx) binding induced visible alterations within the selectivity filter leading to a wider open pore conformation, somewhat supporting the dilated pore phenotype observed previously (Chung et al., 2008; Cao et al., 2013b). This evidence also suggests the existence of different activation pathways for the agonists, despite the close proximity of their respective binding pockets. Capsazepin (CPZ) is a potent TRPV1 antagonist and in the same way it is observed for capsaicin, residues I514 and V518 from TM3, M547 from TM4, as well as residues located on TM2-TM3 linker are candidates to line the CPZ binding pocket (Phillips, 2004). Following the same trend, several residues in TM2 of TRPM8 have been implicated in menthol- (Bandell et al., 2006) and icilin-dependent activation (Chuang et al., 2004). Amino acids within or near the intracellular TM2-TM3 linker have also been suggested as ligand-binding residues (Voets et al., 2007). Bandell and colleagues have performed a high throughput mutagenesis analysis on TRPM8 channels (Bandell et al., 2006). One interesting outcome is that residues from the TM2 helix were only participating in menthol- and icilin-dependent activation, dissecting the ligand activation mechanism from the other sensory cues (i.e., temperature or voltage). The analogy with TRPV1 is evident, suggesting that the main function of the TM1TM4 region is to serve as a LBD conserved among thermoTRP channels.

\section{VANILLOIDS AND METHYLAMINE DERIVATIVES}

The identification and synthesis of derivatives with different chemical modifications have contributed to obtaining a pattern of structure-function relationships, allowing the elucidation of the chemical environment mediating the interactions of the ligands with their target residues in the receptor. Such methodologies ultimately allow the determination of specific shapes and electrostatic factors that contribute to ligand sensitivity, selectivity, and potency. In the next section we discuss some of the properties of thermoTRP channel ligands.

Several naturally occurring compounds sharing structural similarities with capsaicin also augment the open probability of TRPV1 (Sterner and Szallasi, 1999; Vriens et al., 2008; Figures 3, 4). In this context, structure-activity relationship (SAR) analysis has proved to be a useful tool for understanding not only the effects of capsaicin's analogs, but also to find some structural requirements for competitive antagonism to inhibit the activation of TRPV1 receptors by exogenous and endogenous ligands (Walpole et al., 1993a,b,c; Planells-Cases et al., 2003; Kym et al., 2009). Capsaicin pharmacophore models (Figure 5A) consist of three parts named regions A, B, and C (Szallasi and Blumberg, 1999). In this model, recognition of the binding site is mediated by hydrogen bonds through vanillyl (region A) and amide (region $\mathrm{B}$ ) groups. Hydrophobic interactions occur within region $\mathrm{C}$ through the linear aliphatic chain (3E)-2-methyloct-3ene. These pharmacophoric features are frequently found in most of the identified agonists (Figure 5A) and antagonists (Figure 5B) of TRPV1 receptors. Activity measurements show that potency increases with highly polar functional groups in region $\mathrm{B}$, for example urea and thiourea (Suh et al., 2005; Drizin et al., 2006). Evaluation of more restrictive conformations between regions $\mathrm{B}$ and $\mathrm{C}$ which consequently confer less flexibility to the linker connecting regions $\mathrm{A}$ and $\mathrm{B}$ (Figure $5 \mathrm{C}$ ), enhance the antagonistic effect. Another important factor to consider is the critical role that bioactive conformations play in the design of novel drugs (Gore et al., 2007; Perner et al., 2010). The hypothesized bioactive conformations adopted for agonist and antagonist binding to TRPV1 channels show differences between the polar (B) and hydrophobic (C) regions. This observation helped the identification of several competitive antagonists, characterized by the presence of a heterocyclic system, which maintains the polar nature of region B and its ability to form hydrogen bonds (Jetter et al., 2008; Hawryluk et al., 2010).

RTX is nearly 20 -fold more potent TRPV1 agonist than capsaicin. Its structure consists of a vanillyl group in region A, an ester group in region B and the tricyclic system tetradecan (known as daphnane ring) in the hydrophobic region. The difference in specificity with respect to capsaicin is associated with the functional group alfa, beta-unsaturated alfa-hidroxyketone in the pentameric ring. The absence of this group drives loss of activity, and modifications by $3 \beta, 4 \beta$-diol cause a 50 -fold decrease in potency (Walpole et al., 1996). Thus, the modifications of RTX suggest that the design of capsaicin-inspired pharmacophores can be extended, making identification and design of bioactive ligand conformations possible. This can be achieved through modification of hydrogen bonding and polar interactions, improving both potency and specificity.

The lipophilicity of substituent groups affects the ligandreceptor interaction hydrophobic contacts are critical for TRPV1 activation, which is in good correlation with the hydrophobic pocket present in the TRPV1 structure. Interestingly, the position of substituents influences the bioactive conformation. While the para-position of the ligand modulate the agonist or antagonist effect, the meta- position of the ligand modulate the intensity of the response. All these observations suggest that the ligandbinding sites of TRPV1 possess a high degree of plasticity, allowing for the action of different ligands through different sets of interactions within the same region.

Menthol [(1R,2S,5R)-2-isopropyl-5-methylcyclohexanol], a major component of mint (Figure 4E), possesses known cooling properties due to the activation of its pharmacological target, the cold receptor TRPM8. Interestingly, menthol affects other TRP channels, acting as TRPV3 agonist, and having a dual effect on TRPV1 and TRPA1 (Macpherson et al., 2005; Karashima et al., 2007; Xiao et al., 2008; Willis et al., 2011). Moreover, para-menthane-based TRPM8 ligands such as methylamine derivatives display good structural pharmacophore overlap with TRPV1 ligands (Ortar et al., 2010). A good example is BCTC [4-(3-chloro-pyridin-2-yl)-piperazine-1-carboxylic acid (4-tert-butyl-phenyl)-amide], a potent TRPV1 and TRPM8 
A

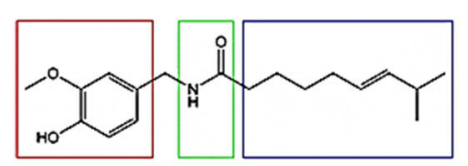

Capsaicin

TRPV1 EC50 : $0.55 \mu \mathrm{M}$

Walpole et al. 1993

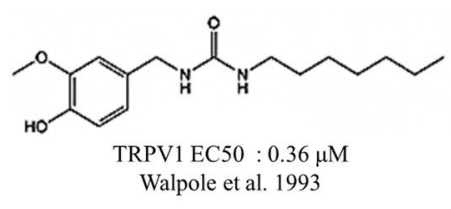<smiles>CCCCCCCCc1cn(Cc2ccc(O)c(OC)c2)nn1</smiles>

TRPV1 EC50 : $0.17 \mu \mathrm{M}$

Appendino et al. 2007

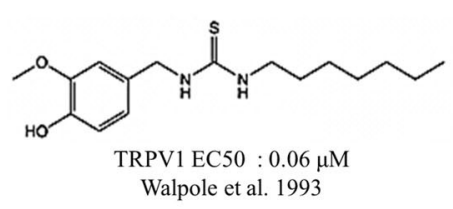

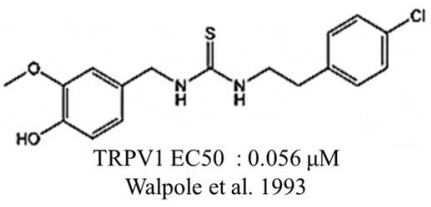

Walpole et al. 1993

B

C
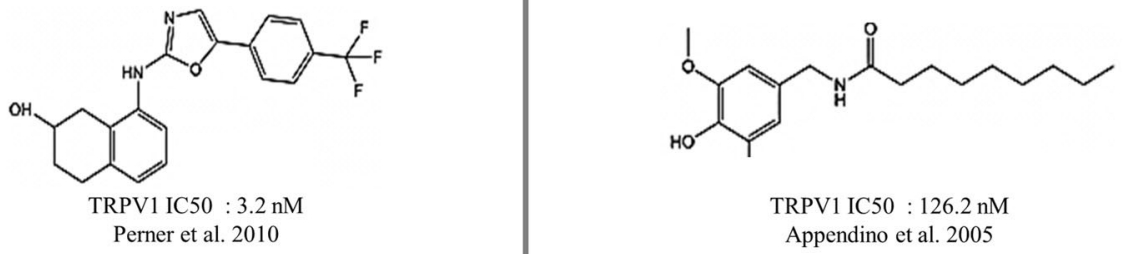

TRPV1 IC50 : $126.2 \mathrm{nM}$

Appendino et al. 2005
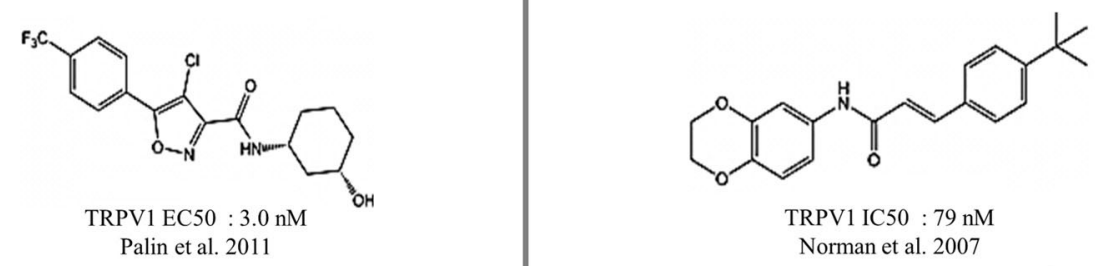

TRPV1 IC50 : $79 \mathrm{nM}$

Norman et al. 2007
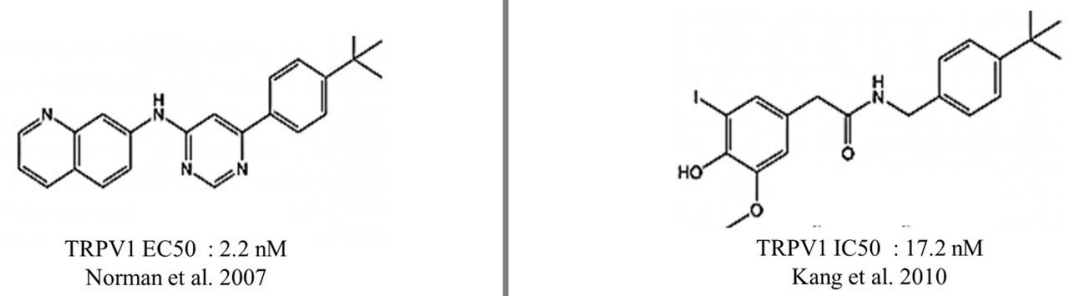

RPV1EC50:2.2 nM

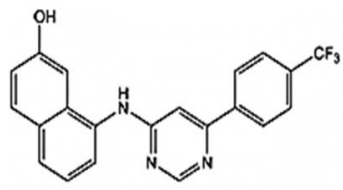

TRPV1 EC50 : $0.65 \mathrm{nM}$

Doherty et al. 2007

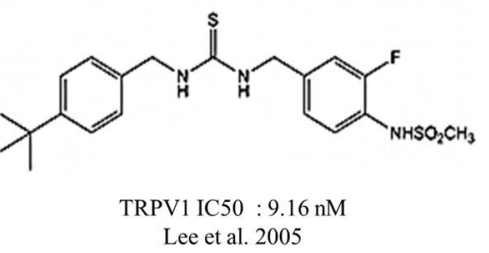

FIGURE 5 | Vanilloids and methylamines as thermoTRP channel ligands. (A) TRPV1 agonist activity. (B) TRPV1 antagonist activity. (C) TRP channel antagonists.

antagonist. SAR analysis for BCTC analogs showed that substitution of the amide group with an ester group reduces the activity of the TRPV1 receptor, while increasing the antagonism of TRPA1 (Morera et al., 2009). Usually non-para-menthane based ligands have an antagonistic effect on TRPM8 channels. One important observation is that the super-cooling agent icilin, is the only non-para-menthane based TRPM8 ligand acting as an agonist (Journigan and Zaveri, 2013). Notably icilin, initially synthesized as a central nervous system depressant (Do and Podesva, 1974), has nearly 200-fold greater efficacy than menthol (McKemy et al., 2002). As for the case of menthol, icilin also has a dual action on TRPA1 channels (Story et al., 2003). 
A

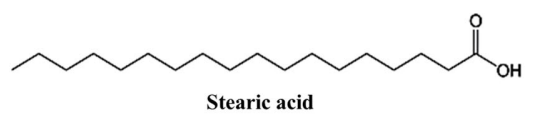

$\mathrm{N}_{\text {Oleic acid }}^{\text {OH }}$

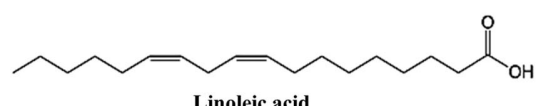

$\sim 2$

$\alpha$-Linoleic acid

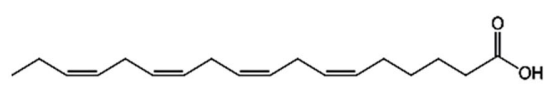

Stearidonic acid

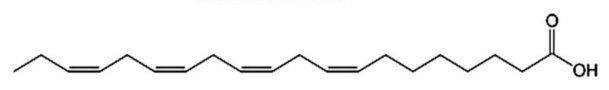

n-3 Arachidonic acid

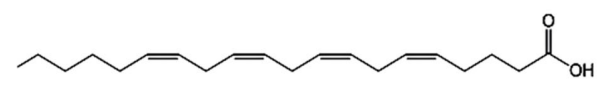

n-6 Arachidonic acid
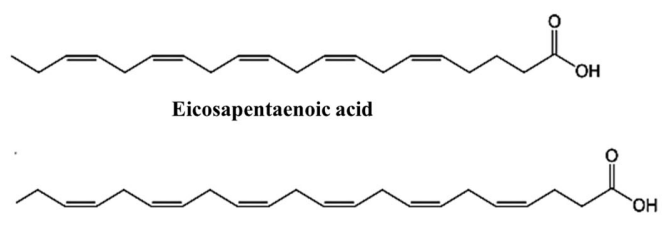

Docosahexaenoic acid
B<smiles>Cc1ccc(NCCCc2ccccc2)cc1</smiles>

TRPA1 EC50 : >100 $\mu \mathrm{M}$<smiles>CCC(=O)Nc1ccc([N+](=O)[O-])cc1C(=O)O</smiles>

TRPA1 EC50 : >100 $\mu \mathrm{M}$<smiles>O=C(O)c1cc([N+](=O)[O-])ccc1Nc1ccccc1</smiles>

TRPA1 EC50 : $13.69 \mu \mathrm{M}$<smiles>O=C(O)c1cc([N+](=O)[O-])ccc1NCCc1ccccc1</smiles>

TRPA1 EC50 $: 5.65 \mu M$<smiles>CC(C)=CCC/C(C)=C/CC/C(C)=C/CSc1ccccc1C(=O)O</smiles>

TRPA1 EC50 : $1.54 \mu \mathrm{M}$<smiles>O=C(O)c1cc([N+](=O)[O-])ccc1NCCCc1ccccc1</smiles>

TRPA1 EC50 $: 0.37 \mu \mathrm{M}$

FIGURE 6 | Fatty acids and lipids as thermoTRP channel ligands. (A) Polyunsaturated fatty acids (PUFAs) evaluated on TRPV1 and TRPA1 receptors (Matta et al., 2007; Motter and Ahern, 2012). (B) 5-nitro-2-(3-phenylpropylamino) benzoic acid derivatives evaluated on TRPA1 receptors (Liu et al., 2010).

\section{GENERALIZING THE ACTION OF PUFAs OVER HOT AND COLD RECEPTORS}

Omega-3 polyunsaturated fatty acids (PUFAs) and some of their derivatives, for example farnesyl thiosalicylic acid (Maher et al., 2008) and 5-nitro-2-(3-phenylpropylamino) benzoic acid (NPPB) (Liu et al., 2010) are moderate agonists of TRPV1 (Matta et al., 2007) and TRPA1 (Motter and Ahern, 2012). Lipids bind differently on TRPV1 compared with capsaicin (Figure 1C). SAR analysis of PUFAs indicates that the aromatic ring is critical for their action. On the other hand, increasing unsaturation of the fatty acid polar domain promotes a more potent response (Figures 6A,B).

The inherent promiscuity of thermoTRP's is evident in the case of leucettamols, a class of marine sphingolipids. While the majority of leucettamols act as TRPM8 inhibitors and TRPA1 activators, only leucettamol B acts as a TRPV1 agonist (Chianese et al., 2012) (Figure 4A). Interestingly, both PUFAs and leucettamols display an unsaturated system, however PUFAs possess a carboxylic acid at the polar region, while leucettamols contain two amine and two hydroxyl groups (Figure 4A). Since PUFAs are general TRPV1 activators, it has been suggested that agonist activity toward TRPV1 is mainly influenced by a polar component that favors ligand recognition, leading to channel opening. An equivalent mechanism could be envisioned for the antagonistic effect observed in TRPM8 receptors, which will be leaded by a less polar component of the leucettamol molecule.

\section{CONCLUDING REMARKS}

It has been reported that an extensive number of natural compounds of aliphatic nature either endogenous or exogenous, and synthetic compounds modulate thermoTRP channel activity. In the present review we illustrate that thermoTRP channel 
ligand-binding sites engage different electrostatic, hydrophobic and steric factors, while retaining a set of conserved structural features shared by all members. General rules can be drawn for ligand stabilization to the bioactive conformation which seems to be highly promoted by the existence of polar contacts and rigidness of the molecule, primarily affecting agonist activity and potency responses. Weaker interactions such as hydrogen bonds are likely involved in defining ligand response as agonistic or antagonistic. The recently released structural data of TRPV1 channels will allow for the exploration of all these differences. Molecular docking studies together with site-directed mutagenesis are likely to be useful in helping to solve these questions; computational methods are emerging as powerful tools which have the potential to support iterative cycles of theoretical prediction, experimental testing and further refinement to achieve greater understanding.

\section{ACKNOWLEDGMENTS}

We thank the members of the Brauchi Laboratory for their useful insights and C. K. Colenso for helpful comments on the manuscript. Ximena Steinberg is a CONICYT and MECESUP fellow. This work was supported by FONDECYT grant 1110906 . The Brauchi Laboratory is part of CISNe-UACh and UACh Program in Cellular Dynamics and Microscopy.

\section{REFERENCES}

Alawi, K., and Keeble, J. (2010). The paradoxical role of the transient receptor potential vanilloid 1 receptor in inflammation. Pharmacol. Ther. 125, 181-195. doi: 10.1016/j.pharmthera.2009.10.005

Amiri, H., Schultz, G., and Schaefer, M. (2003). FRET-based analysis of TRPC subunit stoichiometry. Cell Calcium 33, 463-470. doi: 10.1016/S01434160(03)00061-7

Bandell, M., Dubin, A. E., Petrus, M. J., Orth, A., Mathur, J., Hwang, S. W., et al. (2006). High-throughput random mutagenesis screen reveals TRPM8 residues specifically required for activation by menthol. Nat. Neurosci. 9, 493-500. doi: $10.1038 / \mathrm{nn} 1665$

Boukalova, S., Teisinger, J., and Vlachova, V. (2013). Protons stabilize the closed conformation of gain-of-function mutants of the TRPV1 channel. Biochim. Biophys. Acta 1833, 520-528. doi: 10.1016/j.bbamcr.2012.11.017

Brauchi, S., Orta, G., Mascayano, C., Salazar, M., Raddatz, N., Urbina, H., et al. (2007). Dissection of the components for PIP2 activation and thermosensation in TRP channels. Proc. Natl. Acad. Sci. U.S.A. 104, 10246-10251. doi: 10.1073/pnas.0703420104

Cao, E., Cordero-Morales, J. F., Liu, B., Qin, F., and Julius, D. (2013a). TRPV1 channels are intrinsically heat sensitive and negatively regulated by phosphoinositide lipids. Neuron 77, 667-679. doi: 10.1016/j.neuron.2012.12.016

Cao, E., Liao, M., Cheng, Y., and Julius, D. (2013b). TRPV1 structures in distinct conformations reveal activation mechanisms. Nature 504, 113-118. doi: 10.1038 /nature 12823

Caterina, M. J., and Julius, D. (1999). Sense and specificity: a molecular identity for nociceptors. Curr. Opin. Neurobiol. 9, 525-530. doi: 10.1016/S09594388(99)00009-4

Caterina, M. J., Schumacher, M. A., Tominaga, M., Rosen, T. A., Levine, J. D., and Julius, D. (1997). The capsaicin receptor: a heat-activated ion channel in the pain pathway. Nature 389, 816-824. doi: 10.1038/39807

Cesare, P., and McNaughton, P. (1996). A novel heat-activated current in nociceptive neurons and its sensitization by bradykinin. Proc. Natl. Acad. Sci. U.S.A. 93, 15435-15439. doi: 10.1073/pnas.93.26.15435

Chen, X., Wang, Q., Ni, F., and Ma, J. (2010). Structure of the full-length Shaker potassium channel Kv1.2 by normal-mode-based X-ray crystallographic refinement. Proc. Natl. Acad. Sci. U.S.A. 107, 11352-11357. doi: 10.1073/pnas.1000142107

Chianese, G., Fattorusso, E., Putra, M. Y., Calcinai, B., Bavestrello, G., Moriello, A. S., et al. (2012). Leucettamols, bifunctionalized marine sphingoids, act as modulators of TRPA1 and TRPM8 channels. Mar. Drugs 10, 2435-2447. doi: $10.3390 / \mathrm{md} 10112435$

Chuang, H., Neuhausser, W. M., and Julius, D. (2004). The super-cooling agent icilin reveals a mechanism of coincidence detection by a temperature-sensitive TRP channel. Neuron 43, 859-869. doi: 10.1016/j.neuron.2004.08.038

Chung, M.-K., Güler, A. D., and Caterina, M. J. (2008). TRPV1 shows dynamic ionic selectivity during agonist stimulation. Nat. Neurosci. 11, 555-564. doi: 10.1038/nn.2102

Clapham, D. E. (2003). TRP channels as cellular sensors. Nature 426, 517-524. doi: 10.1038 /nature02196

Clapham, D. E. (2009). "Transient receptor potential (TRP) channels," in Encyclopedia of Neuroscience, ed L. R. Squire. Available online at: http://clapham. tch.harvard.edu/publications/pdf/01634.pdf

Clayton, G. M., Altieri, S., Heginbotham, L., Unger, V. M., and Morais-Cabral, J. H. (2008). Structure of the transmembrane regions of a bacterial cyclic nucleotide-regulated channel. Proc. Natl. Acad. Sci. U.S.A. 105, 1511-1515. doi: 10.1073/pnas.0711533105

De-la-Rosa, V., Rangel-Yescas, G. E., Ladron-de-Guevara, E., Rosenbaum, T., and Islas, L. D. (2013). Coarse Architecture of the Transient Receptor Potential Vanilloid 1 (TRPV1) ion channel determined by fluorescence resonance energy transfer. J. Biol. Chem. 288, 29506-29517. doi: 10.1074/jbc.M113. 479618

De Petrocellis, L., Vellani, V., Schiano-Moriello, A., Marini, P., Magherini, P. C., Orlando, P., et al. (2008). Plant-derived cannabinoids modulate the activity of transient receptor potential channels of Ankyrin Type-1 and Melastatin Type-8. J. Pharmacol. Exp. Ther. 325, 1007-1015. doi: 10.1124/jpet.107.134809

Di Marzo, V., Blumberg, P. M., and Szallasi, A. (2002). Endovanilloid signaling in pain. Curr. Opin. Neurobiol. 12, 372-379. doi: 10.1016/S0959-4388(02)00340-9

Do, N. J., and Podesva, C. (1974). 1,2,3,6-tetrahydropyrimidine-2-One Compounds and Processes for Makingthem. Available online at: https://www.google.co.in/ patents/US3821221

Doerner, J. F., Hatt, H., and Ramsey, I. S. (2011). Voltage- and temperaturedependent activation of TRPV3 channels is potentiated by receptor-mediated PI(4,5)P2 hydrolysis. J. Gen. Physiol. 137, 271-288. doi: 10.1085/jgp.200910388

Dougherty, D. A. (1996). Cation-pi interactions in chemistry and biology: a new view of benzene, Phe, Tyr, and Trp. Science 271, 163-168. doi: 10.1126/science.271.5246.163

Drizin, I., Gomtsyan, A., Bayburt, E. K., Schmidt, R. G., Zheng, G. Z., Perner, R. J., et al. (2006). Structure-activity studies of a novel series of 5,6-fused heteroaromatic ureas as TRPV1 antagonists. Bioorg. Med. Chem. 14, 4740-4749. doi: 10.1016/j.bmc.2006.03.027

Dux, M., Sántha, P., and Jancsó, G. (2012). The role of chemosensitive afferent nerves and TRP ion channels in the pathomechanism of headaches. Pflüg. Arch. Eur. J. Physiol. 464, 239-248. doi: 10.1007/s00424-012-1142-7

Fernández-Ballester, G., and Ferrer-Montiel, A. (2008). Molecular modeling of the full-length human TRPV1 channel in closed and desensitized states. J. Membr. Biol. 223, 161-172. doi: 10.1007/s00232-008-9123-7

Ferrer-Montiel, A., Garcia-Martinez, C., Morenilla-Palao, C., Garcia-Sanz, N., Fernandez-Carvajal, A., Fernandez-Ballester, G., et al. (2004). Molecular architecture of the vanilloid receptor. Insights for drug design. Eur. J. Biochem. 271, 1820-1826. doi: 10.1111/j.1432-1033.2004.04083.x

Fujita, F., Uchida, K., Takaishi, M., Sokabe, T., and Tominaga, M. (2013). Ambient temperature affects the temperature threshold for TRPM8 activation through interaction of Phosphatidylinositol 4,5-Bisphosphate. J. Neurosci. 33, 6154-6159. doi: 10.1523/JNEUROSCI.5672-12.2013

Garcia-Elias, A., Mrkonjic, S., Pardo-Pastor, C., Inada, H., Hellmich, U. A., Rubio-Moscardó, F., et al. (2013). Phosphatidylinositol-4,5-biphosphatedependent rearrangement of TRPV4 cytosolic tails enables channel activation by physiological stimuli. Proc. Natl. Acad. Sci. U.S.A. 110, 9553-9558. doi: 10.1073/pnas.1220231110

Garcia-Sanz, N., Valente, P., Gomis, A., Fernandez-Carvajal, A., FernandezBallester, G., Viana, F., et al. (2007). A role of the transient receptor potential domain of vanilloid receptor I in channel gating. J. Neurosci. 27, 11641-11650. doi: 10.1523/JNEUROSCI.2457-07.2007

Gavva, N. R., Klionsky, L., Qu, Y., Shi, L., Tamir, R., Edenson, S., et al. (2004). Molecular determinants of vanilloid sensitivity in TRPV1. J. Biol. Chem. 279, 20283-20295. doi: 10.1074/jbc.M312577200

Gore, V. K., Ma, V. V., Tamir, R., Gavva, N. R., Treanor, J. J. S., and Norman, M. H. (2007). Structure-activity relationship (SAR) investigations of substituted 
imidazole analogs as TRPV1 antagonists. Bioorg. Med. Chem. Lett. 17, 5825-5830. doi: 10.1016/j.bmcl.2007.08.044

Gregorio-Teruel, L., Valente, P., González-Ros, J. M., Fernández-Ballester, G., and Ferrer-Montiel, A. (2014). Mutation of I696 and W697 in the TRP box of vanilloid receptor subtype I modulates allosteric channel activation. J. Gen. Physiol. 143, 361-375. doi: 10.1085/jgp.201311070

Hansen, S. B., Tao, X., and MacKinnon, R. (2011). Structural basis of PIP2 activation of the classical inward rectifier K+ channel Kir2.2. Nature 477, 495-498. doi: 10.1038/nature 10370

Harteneck, C., Plant, T. D., and Schultz, G. (2000). From worm to man: three subfamilies of TRP channels. Trends Neurosci. 23, 159-166. doi: 10.1016/S01662236(99)01532-5

Hawryluk, N. A., Merit, J. E., Lebsack, A. D., Branstetter, B. J., Hack, M. D., Swanson, N., et al. (2010). Discovery and synthesis of 6,7,8,9-tetrahydro-5Hpyrimido-[4,5-d]azepines as novel TRPV1 antagonists. Bioorg. Med. Chem. Lett. 20, 7137-7141. doi: 10.1016/j.bmcl.2010.09.023

Hwang, S. W., Cho, H., Kwak, J., Lee, S. Y., Kang, C. J., Jung, J., et al. (2000). Direct activation of capsaicin receptors by products of lipoxygenases: endogenous capsaicin-like substances. Proc. Natl. Acad. Sci. U.S.A. 97, 6155-6160. doi: 10.1073/pnas.97.11.6155

Immke, D. C., and Gavva, N. R. (2006). The TRPV1 receptor and nociception. Semin. Cell Dev. Biol. 17, 582-591. doi: 10.1016/j.semcdb.2006.09.004

Jahnel, R., Dreger, M., Gillen, C., Bender, O., Kurreck, J., and Hucho, F. (2001). Biochemical characterization of the vanilloid receptor 1 expressed in a dorsal root ganglia derived cell line. Eur. J. Biochem. 268, 5489-5496. doi: 10.1046/j.1432-1033.2001.02500.x

Jetter, M. C., McNally, J. J., Youngman, M. A., McDonnell, M. E., Dubin, A. E., Nasser, N., et al. (2008). N-pyridin-3-yl- and N-quinolin-3-yl-benzamides: modulators of human vanilloid receptor 1 (TRPV1). Bioorg. Med. Chem. Lett. 18, 2730-2734. doi: 10.1016/j.bmcl.2008.02.075

Jordt, S.-E., and Julius, D. (2002). Molecular basis for species-specific sensitivity to "hot" chili peppers. Cell 108, 421-430. doi: 10.1016/S0092-8674(02)00637-2

Journigan, V. B., and Zaveri, N. T. (2013). TRPM8 ion channel ligands for new therapeutic applications and as probes to study menthol pharmacology. Life Sci. 92, 425-437. doi: 10.1016/j.lfs.2012.10.032

Julius, D. (2013). TRP channels and pain. Annu. Rev. Cell Dev. Biol. 29, 355-384. doi: 10.1146/annurev-cellbio-101011-155833

Kalia, J., and Swartz, K. J. (2013). Exploring structure-function relationships between TRP and Kv channels. Sci. Rep. 3:1523. doi: 10.1038/srep01523

Karashima, Y., Damann, N., Prenen, J., Talavera, K., Segal, A., Voets, T., et al. (2007). Bimodal action of menthol on the transient receptor potential channel TRPA1. J. Neurosci. 27, 9874-9884. doi: 10.1523/JNEUROSCI.2221-07.2007

Kedei, N. (2001). Analysis of the native quaternary structure of vanilloid receptor 1. J. Biol. Chem. 276, 28613-28619. doi: 10.1074/jbc.M103272200

Kruse, M., Hammond, G. R. V., and Hille, B. (2012). Regulation of voltagegated potassium channels by PI(4,5)P2. J. Gen. Physiol. 140, 189-205. doi: 10.1085/jgp.201210806

Kym, P. R., Kort, M. E., and Hutchins, C. W. (2009). Analgesic potential of TRPV1 antagonists. Biochem. Pharmacol. 78, 211-216. doi: 10.1016/j.bcp.2009.02.014

Latorre, R., Brauchi, S., Orta, G., Zaelzer, C., and Vargas, G. (2007). ThermoTRP channels as modular proteins with allosteric gating. Cell Calcium 42, 427-438. doi: 10.1016/j.ceca.2007.04.004

Latorre, R., Zaelzer, C., and Brauchi, S. (2009). Structure-functional intimacies of transient receptor potential channels. Q. Rev. Biophys. 42, 201. doi: $10.1017 /$ S0033583509990072

Lee, S. P., Buber, M. T., Yang, Q., Cerne, R., Cortés, R. Y., Sprous, D. G., et al. (2008). Thymol and related alkyl phenols activate the hTRPAl channel. Br. J. Pharmacol. 153, 1739-1749. doi: 10.1038/bjp.2008.85

Le Roy, C., and Wrana, J. L. (2005). Clathrin- and non-clathrin-mediated endocytic regulation of cell signalling. Nat. Rev. Mol. Cell Biol. 6, 112-126. doi: $10.1038 / \mathrm{nrm} 1571$

Li, M., Yu, Y., and Yang, J. (2011). "Structural biology of TRP channels," in Transient Receptor Potential Channels, ed M. S. Islam (Dordrecht: Springer Netherlands), 1-23. Available online at: http://link.springer.com/10.1007/978-94-007-0265-3_1 (Accessed March $10,2014)$.

Liao, M., Cao, E., Julius, D., and Cheng, Y. (2013). Structure of the TRPV1 ion channel determined by electron cryo-microscopy. Nature 504, 107-112. doi: 10.1038 /nature 12822
Liu, K., Samuel, M., Ho, M., Harrison, R. K., and Paslay, J. W. (2010). NPPB structure-specifically activates TRPA1 channels. Biochem. Pharmacol. 80, 113-121. doi: 10.1016/j.bcp.2010.03.005

Long, S. B., Campbell, E. B., and Mackinnon, R. (2005). Crystal structure of a mammalian voltage-dependent shaker family K+ channel. Science 309, 897-903. doi: 10.1126/science. 1116269

Lukacs, V., Rives, J.-M., Sun, X., Zakharian, E., and Rohacs, T. (2013). Promiscuous Activation of Transient Receptor Potential Vanilloid 1 (TRPV1) channels by negatively charged intracellular lipids: the key role of endogenous phosphoinositides in maintaining channel activity. J. Biol. Chem. 288, 35003-35013. doi: 10.1074/jbc.M113.520288

Macpherson, L. J., Dubin, A. E., Evans, M. J., Marr, F., Schultz, P. G., Cravatt, B. F., et al. (2007). Noxious compounds activate TRPAl ion channels through covalent modification of cysteines. Nature 445, 541-545. doi: 10.1038/nature05544

Macpherson, L. J., Geierstanger, B. H., Viswanath, V., Bandell, M., Eid, S. R., Hwang, S., et al. (2005). The pungency of garlic: activation of TRPA1 and TRPV1 in response to allicin. Curr. Biol. 15, 929-934. doi: 10.1016/j.cub.2005.04.018

Maher, M., Ao, H., Banke, T., Nasser, N., Wu, N.-T., Breitenbucher, J. G., et al. (2008). Activation of TRPA1 by farnesyl thiosalicylic acid. Mol. Pharmacol. 73, 1225-1234. doi: 10.1124/mol.107.042663

Mandadi, S., and Roufogalis, B. D. (2008). ThermoTRP channels in nociceptors: taking a lead from capsaicin receptor TRPV1. Curr. Neuropharmacol. 6, 21-38. doi: 10.2174/157015908783769680

Maruyama, Y., Ogura, T., Mio, K., Kiyonaka, S., Kato, K., Mori, Y., et al. (2007). Three-dimensional reconstruction using transmission electron microscopy reveals a swollen, bell-shaped structure of transient receptor potential melastatin type 2 cation channel. J. Biol. Chem. 282, 36961-36970. doi: 10.1074/jbc.M705694200

Matta, J. A., Miyares, R. L., and Ahern, G. P. (2007). TRPV1 is a novel target for omega-3 polyunsaturated fatty acids. J. Physiol. 578, 397-411. doi: 10.1113/jphysiol.2006.121988

McKemy, D. D., Neuhausser, W. M., and Julius, D. (2002). Identification of a cold receptor reveals a general role for TRP channels in thermosensation. Nature 416, 52-58. doi: 10.1038/nature719

Messeguer, A., Planells-Cases, R., and Ferrer-Montiel, A. (2006). Physiology and pharmacology of the vanilloid receptor. Curr. Neuropharmacol. 4, 1-15. doi: $10.2174 / 157015906775202995$

Mio, K., Ogura, T., Kiyonaka, S., Hiroaki, Y., Tanimura, Y., Fujiyoshi, Y., et al. (2007). The TRPC3 channel has a large internal chamber surrounded by signal sensing antennas. J. Mol. Biol. 367, 373-383. doi: 10.1016/j.jmb.2006. 12.043

Moiseenkova-Bell, V. Y., Stanciu, L. A., Serysheva, I. I., Tobe, B. J., and Wensel, T. G. (2008). Structure of TRPV1 channel revealed by electron cryomicroscopy. Proc. Natl. Acad. Sci. U.S.A. 105, 7451-7455. doi: 10.1073/pnas.0711835105

Montell, C. (2005). The TRP superfamily of cation channels. Sci. STKE 2005, re3. doi: $10.1126 /$ stke.2722005re3

Morales-Lázaro, S. L., Simon, S. A., and Rosenbaum, T. (2013). The role of endogenous molecules in modulating pain through transient receptor potential vanilloid 1 (TRPV1). J. Physiol. 591, 3109-3121. doi: 10.1113/jphysiol.2013. 251751

Morera, E., De Petrocellis, L., Morera, L., Moriello, A. S., Ligresti, A., Nalli, M., et al. (2009). Synthesis and biological evaluation of piperazinyl carbamates and ureas as fatty acid amide hydrolase (FAAH) and transient receptor potential (TRP) channel dual ligands. Bioorg. Med. Chem. Lett. 19, 6806-6809. doi: 10.1016/j.bmcl.2009.09.033

Motter, A. L., and Ahern, G. P. (2012). TRPA1 is a polyunsaturated fatty acid sensor in mammals. PLoS ONE 7:e38439. doi: 10.1371/journal.pone.0038439

Nilius, B. (2007). TRP channels in disease. Biochim. Biophys. Acta 1772, 805-812. doi: 10.1016/j.bbadis.2007.02.002

Nilius, B., Owsianik, G., and Voets, T. (2008). Transient receptor potential channels meet phosphoinositides. EMBO J. 27, 2809-2816. doi: 10.1038/emboj.2008.217

Ortar, G., De Petrocellis, L., Morera, L., Moriello, A. S., Orlando, P., Morera, E., et al. (2010). (-)-Menthylamine derivatives as potent and selective antagonists of transient receptor potential melastatin type-8 (TRPM8) channels. Bioorg. Med. Chem. Lett. 20, 2729-2732. doi: 10.1016/j.bmcl.2010.03.076

Owsianik, G., D'hoedt, D., Voets, T., and Nilius, B. (2006). Structure-function relationship of the TRP channel superfamily. Rev. Physiol. Biochem. Pharmacol. 156, 61-90. doi: 10.1007/s10254-005-0006-0 
Palazzo, E., Rossi, F., de Novellis, V., and Maione, S. (2013). Endogenous modulators of TRP channels. Curr. Top. Med. Chem. 13, 398-407. doi: $10.2174 / 1568026611313030014$

Patapoutian, A. (2005). TRP channels and thermosensation. Chem. Senses 30(Suppl. 1), i193-194. doi: 10.1093/chemse/bjh180

Pedretti, A., Labozzetta, A., Lo Monte, M., Beccari, A. R., Moriconi, A., and Vistoli, G. (2011). Exploring the activation mechanism of TRPM8 channel by targeted MD simulations. Biochem. Biophys. Res. Commun. 414, 14-19. doi: 10.1016/j.bbrc.2011.08.134

Pedretti, A., Marconi, C., Bettinelli, I., and Vistoli, G. (2009). Comparative modeling of the quaternary structure for the human TRPM8 channel and analysis of its binding features. Biochim. Biophys. Acta 1788, 973-982. doi: 10.1016/j.bbamem.2009.02.007

Perner, R. J., Koenig, J. R., Didomenico, S., Gomtsyan, A., Schmidt, R. G., Lee, C.H., et al. (2010). Synthesis and biological evaluation of 5-substituted and 4,5disubstituted-2-arylamino oxazole TRPV1 antagonists. Bioorg. Med. Chem. 18, 4821-4829. doi: 10.1016/j.bmc.2010.04.099

Pertusa, M., Moldenhauer, H., Brauchi, S., Latorre, R., Madrid, R., and Orio, P. (2012). "Mutagenesis and temperature-sensitive little machines," in Mutagenesis, ed R. Mishra (InTech). Available online at: http://www.intechopen.com/books/mutagenesis/mutagenesisand-temperature-sensitive-little-machines (Accessed January 18, 2014).

Phillips, A. M., Bull, A., and Kelly, L. E. (1992). Identification of a Drosophila gene encoding a calmodulin-binding protein with homology to the trp phototransduction gene. Neuron 8, 631-642. doi: 10.1016/0896-6273(92)90085-R

Phillips, E. (2004). Identification of species-specific determinants of the action of the antagonist capsazepine and the agonist PPAHV on TRPV1. J. Biol. Chem. 279, 17165-17172. doi: 10.1074/jbc.M313328200

Planells-Cases, R., Garcia-Martinez, C., Royo, M., Perez-Pay, E., Carreño, C., Albericio, F., et al. (2003). Small molecules targeting the vanilloid receptor complex as drugs for inflammatory pain. Drugs Future 28, 787. doi: 10.1358/dof.2003.028.08.747395

Poveda, J. A., Giudici, A. M., Renart, M. L., Molina, M. L., Montoya, E., Fernández-Carvajal, A., et al. (2013). Lipid modulation of ion channels through specific binding sites. Biochim. Biophys. Acta. 1838, 1560-1567. doi: 10.1016/j.bbamem.2013.10.023

Prescott, E. D., and Julius, D. (2003). A modular PIP2 binding site as a determinant of capsaicin receptor sensitivity. Science 300, 1284-1288. doi: 10.1126/science. 1083646

Ramachandran, R., Hyun, E., Zhao, L., Lapointe, T. K., Chapman, K., Hirota, C. L., et al. (2013). TRPM8 activation attenuates inflammatory responses in mouse models of colitis. Proc. Natl. Acad. Sci. U.S.A. 110, 7476-7481. doi: $10.1073 /$ pnas. 1217431110

Ramsey, I. S., Delling, M., and Clapham, D. E. (2006). An introduction to TRP channels. Annu. Rev. Physiol. 68, 619-647. doi: 10.1146/annurev.physiol.68.040204.100431

Rohacs, T. (2009). Phosphoinositide regulation of non-canonical transient receptor potential channels. Cell Calcium 45, 554-565. doi: 10.1016/j.ceca.2009. 03.011

Rohács, T., Lopes, C. M. B., Michailidis, I., and Logothetis, D. E. (2005). PI(4,5)P2 regulates the activation and desensitization of TRPM8 channels through the TRP domain. Nat. Neurosci. 8, 626-634. doi: 10.1038/nn1451

Rohacs, T., Thyagarajan, B., and Lukacs, V. (2008). Phospholipase C mediated modulation of TRPV1 channels. Mol. Neurobiol. 37, 153-163. doi: 10.1007/s12035008-8027-y

Salazar, H., Jara-Oseguera, A., Hernández-García, E., Llorente, I., Arias-Olguín, I. I., Soriano-García, M., et al. (2009). Structural determinants of gating in the TRPV1 channel. Nat. Struct. Mol. Biol. 16, 704-710. doi: 10.1038/ nsmb.1633

Sherkheli, M. A., Vogt-Eisele, A. K., Bura, D., Beltrán Márques, L. R., Gisselmann, G., and Hatt, H. (2010). Characterization of selective TRPM8 ligands and their structure activity response (S.A.R) relationship. J. Pharm. Pharm. Sci. 13, 242-253.

Stein, C., Clark, J. D., Oh, U., Vasko, M. R., Wilcox, G. L., Overland, A. C., et al. (2009). Peripheral mechanisms of pain and analgesia. Brain Res. Rev. 60, 90-113. doi: 10.1016/j.brainresrev.2008.12.017

Sterner, O., and Szallasi, A. (1999). Novel natural vanilloid receptor agonists: new therapeutic targets for drug development. Trends Pharmacol. Sci. 20, 459-465. doi: 10.1016/S0165-6147(99)01393-0
Story, G. M., Peier, A. M., Reeve, A. J., Eid, S. R., Mosbacher, J., Hricik, T. R., et al. (2003). ANKTM1, a TRP-like channel expressed in nociceptive neurons, is activated by cold temperatures. Cell 112, 819-829. doi: 10.1016/S00928674(03)00158-2

Straub, I., Krügel, U., Mohr, F., Teichert, J., Rizun, O., Konrad, M., et al. (2013). Flavanones that selectively inhibit TRPM3 attenuate thermal nociception in vivo. Mol. Pharmacol. 84, 736-750. doi: 10.1124/mol.113.086843

Suh, Y.-G., Lee, Y.-S., Min, K.-H., Park, O.-H., Kim, J.-K., Seung, H.-S., et al. (2005). Novel potent antagonists of transient receptor potential channel, vanilloid subfamily member 1: structure-activity relationship of 1,3-diarylalkyl thioureas possessing new vanilloid equivalents. J. Med. Chem. 48, 5823-5836. doi: $10.1021 /$ jm0502790

Susankova, K., Ettrich, R., Vyklicky, L., Teisinger, J., and Vlachova, V. (2007). Contribution of the putative inner-pore region to the gating of the transient receptor potential vanilloid subtype 1 channel (TRPV1). J. Neurosci. 27, 7578-7585. doi: 10.1523/JNEUROSCI.1956-07.2007

Szallasi, A., and Blumberg, P. M. (1999). Vanilloid (Capsaicin) receptors and mechanisms. Pharmacol. Rev. 51, 159-212.

Takaishi, M., Fujita, F., Uchida, K., Yamamoto, S., Sawada Shimizu, M., Hatai Uotsu, C., et al. (2012). 1,8-cineole, a TRPM8 agonist, is a novel natural antagonist of human TRPA1. Mol. Pain 8:86. doi: 10.1186/1744-8069-8-86

Taylor-Clark, T. E., Undem, B. J., Macglashan, D. W. Jr., Ghatta, S., Carr, M. J., and McAlexander, M. A. (2008). Prostaglandin-induced activation of nociceptive neurons via direct interaction with transient receptor potential A1 (TRPA1). Mol. Pharmacol. 73, 274-281. doi: 10.1124/mol.107.040832

Tominaga, M., Caterina, M. J., Malmberg, A. B., Rosen, T. A., Gilbert, H., Skinner, K., et al. (1998). The cloned capsaicin receptor integrates multiple painproducing stimuli. Neuron 21, 531-543. doi: 10.1016/S0896-6273(00)80564-4

Ufret-Vincenty, C. A., Klein, R. M., Hua, L., Angueyra, J., and Gordon, S. E. (2011). Localization of the PIP2 Sensor of TRPV1 Ion Channels. J. Biol. Chem. 286, 9688-9698. doi: 10.1074/jbc.M110.192526

Valente, P., García-Sanz, N., Gomis, A., Fernández-Carvajal, A., FernándezBallester, G., Viana, F., et al. (2008). Identification of molecular determinants of channel gating in the transient receptor potential box of vanilloid receptor I. FASEB J. 22, 3298-3309. doi: 10.1096/fj.08-107425

Veliz, L. A., Toro, C. A., Vivar, J. P., Arias, L. A., Villegas, J., Castro, M. A., et al. (2010). Near-membrane dynamics and capture of TRPM8 channels within transient confinement domains. PLoS ONE 5:e13290. doi: 10.1371/journal.pone.0013290

Voets, T., Owsianik, G., Janssens, A., Talavera, K., and Nilius, B. (2007). TRPM8 voltage sensor mutants reveal a mechanism for integrating thermal and chemical stimuli. Nat. Chem. Biol. 3, 174-182. doi: 10.1038/nchembio862

Voets, T., Talavera, K., Owsianik, G., and Nilius, B. (2005). Sensing with TRP channels. Nat. Chem. Biol. 1, 85-92. doi: 10.1038/nchembio0705-85

Vogt-Eisele, A. K., Weber, K., Sherkheli, M. A., Vielhaber, G., Panten, J., Gisselmann, G., et al. (2007). Monoterpenoid agonists of TRPV3. Br. J. Pharmacol. 151, 530-540. doi: 10.1038/sj.bjp.0707245

Vriens, J., Nilius, B., and Vennekens, R. (2008). Herbal compounds and toxins modulating TRP channels. Curr. Neuropharmacol. 6, 79-96. doi: $10.2174 / 157015908783769644$

Walpole, C. S., Bevan, S., Bloomfield, G., Breckenridge, R., James, I. F., Ritchie, T., et al. (1996). Similarities and differences in the structure-activity relationships of capsaicin and resiniferatoxin analogues. J. Med. Chem. 39, 2939-2952. doi: $10.1021 / j m 960139 d$

Walpole, C. S., Wrigglesworth, R., Bevan, S., Campbell, E. A., Dray, A., James, I. F., et al. (1993a). Analogues of capsaicin with agonist activity as novel analgesic agents; structure-activity studies. 2 . The amide bond "B-region." J. Med. Chem. 36, 2373-2380. doi: 10.1021/jm00068a015

Walpole, C. S., Wrigglesworth, R., Bevan, S., Campbell, E. A., Dray, A., James, I. F., et al. (1993b). Analogues of capsaicin with agonist activity as novel analgesic agents; structure-activity studies. 3. The hydrophobic side-chain "C-region." J. Med. Chem. 36, 2381-2389. doi: 10.1021/jm00068a016

Walpole, C. S., Wrigglesworth, R., Bevan, S., Campbell, E. A., Dray, A., James, I. F., et al. (1993c). Analogues of capsaicin with agonist activity as novel analgesic agents; structure-activity studies. 1. The aromatic "A-region." J. Med. Chem. 36, 2362-2372. doi: 10.1021/jm00068a014

Wes, P. D., Chevesich, J., Jeromin, A., Rosenberg, C., Stetten, G., and Montell, C. (1995). TRPC1, a human homolog of a Drosophila store-operated channel. Proc. Natl. Acad. Sci. U.S.A. 92, 9652-9656. doi: 10.1073/pnas.92.21.9652 
Whorton, M. R., and MacKinnon, R. (2011). Crystal structure of the mammalian GIRK2 $\mathrm{K}+$ channel and gating regulation by $\mathrm{G}$ proteins, PIP2, and sodium. Cell 147, 199-208. doi: 10.1016/j.cell.2011.07.046

Willis, D. N., Liu, B., Ha, M. A., Jordt, S.-E., and Morris, J. B. (2011). Menthol attenuates respiratory irritation responses to multiple cigarette smoke irritants. FASEB J. 25, 4434-4444. doi: 10.1096/fj.11-188383

Winter, Z., Buhala, A., Ötvös, F., Jósvay, K., Vizler, C., Dombi, G., et al. (2013). Functionally important amino acid residues in the transient receptor potential vanilloid 1 (TRPV1) ion channel-an overview of the current mutational data. Mol. Pain 9, 30. doi: 10.1186/1744-8069-9-30

Xiao, B., Dubin, A. E., Bursulaya, B., Viswanath, V., Jegla, T. J., and Patapoutian, A. (2008). Identification of transmembrane domain 5 as a critical molecular determinant of menthol sensitivity in mammalian TRPA1 channels. J. Neurosci. 28, 9640-9651. doi: 10.1523/JNEUROSCI.2772-08.2008

Yao, J., Liu, B., and Qin, F. (2011). Modular thermal sensors in temperature-gated transient receptor potential (TRP) channels. Proc. Natl. Acad. Sci. U.S.A. 108, 11109-11114. doi: 10.1073/pnas.1105196108

Zagotta, W. N., Olivier, N. B., Black, K. D., Young, E. C., Olson, R., and Gouaux, E. (2003). Structural basis for modulation and agonist specificity of HCN pacemaker channels. Nature 425, 200-205. doi: 10.1038/nature01922

Zhu, X., Chu, P. B., Peyton, M., and Birnbaumer, L. (1995). Molecular cloning of a widely expressed human homologue for the Drosophila trp gene. FEBS Lett. 373, 193-198. doi: 10.1016/0014-5793(95)01038-G
Zimmermann, K., Lennerz, J. K., Hein, A., Link, A. S., Kaczmarek, J. S., Delling, M., et al. (2011). Transient receptor potential cation channel, subfamily C, member 5 (TRPC5) is a cold-transducer in the peripheral nervous system. Proc. Natl. Acad. Sci. U.S.A. 108, 18114-18119. doi: 10.1073/pnas.11153 87108

Conflict of Interest Statement: The authors declare that the research was conducted in the absence of any commercial or financial relationships that could be construed as a potential conflict of interest.

Received: 23 January 2014; accepted: 11 April 2014; published online: 05 May 2014 Citation: Steinberg X, Lespay-Rebolledo C and Brauchi S (2014) A structural view of ligand-dependent activation in thermoTRP channels. Front. Physiol. 5:171. doi: 10.3389/fphys.2014.00171

This article was submitted to Membrane Physiology and Membrane Biophysics, a section of the journal Frontiers in Physiology.

Copyright (C) 2014 Steinberg, Lespay-Rebolledo and Brauchi. This is an openaccess article distributed under the terms of the Creative Commons Attribution License (CC BY). The use, distribution or reproduction in other forums is permitted, provided the original author(s) or licensor are credited and that the original publication in this journal is cited, in accordance with accepted academic practice. No use, distribution or reproduction is permitted which does not comply with these terms. 